\title{
Comparison of Microvessel Density with Prognostic Factors in Invasive Ductal Carcinomas of the Breast
}

\author{
Ebru ŞENER', Sare ŞIPAL' ${ }^{2}$ Cemal GÜNDOĞDU² \\ Department of Pathology, 'Erzurum Regional Training and Research Hospital, ERZURUM, TURKEY, ${ }^{2}$ Ataturk University, Faculty of Medicine, ERZURUM, TURKEY
}

\begin{abstract}
Objective: Angiogenesis plays a key role in tumor growth and metastasis. Determination of microvessel density is the most common technique used to evaluate the amount of the intratumoral angiogenesis in breast cancer. We have aimed to investigate the relationship with tumor angiogenesis and prognostic parameters in breast invasive ductal carcinomas.
\end{abstract}

Material and Method: In this study, a total of 100 invasive ductal carcinoma patients, who were diagnosed at the Department of Pathology, Ataturk University Faculty of Medicine between the years 2003-2008, were re-evaluated. Patient characteristics and clinicopathological findings were obtained from archival records. In the present study, microvessel density was determined by immunohistochemical staining by using anti-CD34 monoclonal antibody in the paraffin blocks. First, the most vascular area was selected in the tumor under a low magnification (40x) by a light microscope and then microvessels were counted under a higher magnification (200x). Patients were classified as low and high microvessel density depending on their microvessel counts. Chi-square test and multivariate linear regression analysis were used for statistical analysis $(\mathrm{p} \leq 0.05)$.

Results: We have determined that microvessel density increases as tumor size increases $(p=0.001)$. Microvessel density was higher in patients with at least 10 lymph node metastases compared to those with no metastasis $(\mathrm{p}=0.05)$. However, there was no statistically significant difference between microvessel density and other prognostic factors such as histological grade, nuclear grade, patient age, vascular invasion, estrogen, progesterone receptor status, HER2/neu expression.

Conclusion: In our study, we have found that microvessel density is associated with tumor size and lymph node metastasis in patients with invasive ductal carcinoma.

Key Words: Breast cancer, Invasive ductal carcinoma, Angiogenesis

\section{INTRODUCTION}

Breast cancer is the most common malignant tumor among women in Turkey and the world. It accounts for approximately $30 \%$ of all cancers in women. According to the 2013 data of Ministry of Health, breast cancer constitutes $24.6 \%$ of all cancers among women in our country and the most common type is invasive ductal carcinoma (1). Therefore, the etiologic and prognostic studies on breast cancer are still important.

Angiogenesis is the process of new capillary vessel formation and it is observed in physiological events such as embryonic development, wound healing and organ hypertrophy. However, uncontrolled angiogenesis is held responsible for the progression and etiopathogenesis of many neoplastic formations, especially growth and metastasis of solid tumors (2). The numerical value of tumor angiogenesis is defined as microvessel density (MVD). MVD is measured by counting small and tortuous vessels in the tumor tissue by immunohistochemical staining using antibodies such as

(Turk Patoloji Derg 2016, 32:164-170)

Received : 14.04.2016 Accepted:05.06.2016
CD31, CD34, CD105 and Von-Willebrand factor (Factor VIII) that are specific for vessel endothelium. In the earlier studies, MVD is reported to be associated with advanced pathologic stage and poor prognosis of disease in breast, lung, colon, stomach, prostate and bladder cancers, and malignant melanoma (3-5).

In this study, we aimed to determine the angiogenesis in invasive ductal carcinoma, which is the most common breast cancer type, by using microvessel counting and the relationship between MVD and known prognostic parameters such as patient's age, tumor size, lymph node metastasis, vascular invasion, estrogen-progesterone receptor status, human epidermal growth factor (HER2/ neu) expression.

\section{MATERIAL and METHOD}

In this study, a total of 113 patients, who were diagnosed with invasive ductal carcinoma, not otherwise specified (NOS) in the Department of Pathology, Atatürk University School of

Correspondence: Ebru ŞENER

Erzurum Bölge Eğitim ve Araştırma Hastanesi, Patoloji Bölümü, ERZURUM, TURKEY

E-mail: ebruomerogullari@gmail.com Phone: +90 5057856871 
Medicine between the years 2003-2008 and did not receive any neo-adjuvant treatment, underwent modified radical mastectomy and axillary lymph node dissection were reevaluated. However, 13 patients were excluded from the study since we could not access their paraffin blocks from the pathology department archive. Hematoxylin and eosin (H\&E) preparations of these patients were re-evaluated and the best formalin fixed-paraffin embedded (FFPE) block representing the tumor for each patient was selected. MVD was determined by immunohistochemical staining with this tissue. Results were compared with clinicopathologic parameters such as patient's age, tumor size, histological grade, lymph node involvement, the presence of vascular invasion, estrogen-progesterone receptor status, human epidermal growth factor (HER2/neu) expression. The data about clinicopathologic features were obtained from the pathology reports. These features were also used to evaluate mastectomy materials during routine pathology practice. The study was approved by the Ethics Committee of Erzurum Ataturk University, School of Medicine.

The Nottingham modification of Bloom-Richardson system was used for histological grading (6). When $1 \%$ and higher nuclear staining was present in the tumor cells at any density, hormone receptor status was accepted as positive. According to immunostaining results, HER2/neu expression was considered as negative $(0,1+)$, equivocal $(2+)$ and positive (3+) (7). Tumor diameter and lymph node status were grouped according to the TNM system.

\section{Immunohistochemistry}

The $5 \mu$ thick samples taken from FFPE blocks of each patient were put on poly-L-lysine coated microscope slides. These samples were washed in phosphate buffered saline (PBS) after deparaffinization with xylene and rehydration process with alcohol. In order to eliminate the endogenous peroxidase activity, they were incubated in $3 \%$ hydrogen peroxide solution for 15 minutes. They were washed again in PBS. Then, anti-CD34 primer antibody (Monoclonal Mouse Anti-human CD 34 class II Clone QBend-10) (Dako code No. M 7165), which was diluted at a ratio of 1:50, was dropped onto tissues and waited for 60 minutes. Tissues were re-washed in PBS. Biotinylated-link was treated for 30 minutes as the secondary antibody. It was re-washed in PBS. Treated with streptavidin peroxidase for 30 minutes and washed in PBS. Tissues were incubated for 6 minutes after dropping chromogenic DAB (3,3'-Diaminobenzidine tetrahydrochloride). The samples washed with distilled water were counterstained with Mayer's hematoxylin and then closed by immunohistochemistry sealing solution after being washed off with distilled water again.

\section{Microvessel Density (MVD) Calculation}

MVD was evaluated by counting anti-CD34 positive microvessels and calculated by the counting method developed by Weidner using a light microscope (8). Accordingly, after scanning the whole tumoral section with a light microscope under a low magnification (x40), the area with highest number of microvessels was identified as 'hot-spot' (Figure 1) and microvessels were counted under a higher magnification (200x) in this area. Any brown-stained single endothelial cell or endothelial cell clusters seperated from surrounding tumor cells and connective tissue elements were considered to be a microvessel regardless of whether they had a lumen or not. No erythrocyte was necessarily required in the lumen. Branching vessel structures were counted as a single vessel. Vascularity was not considered in the areas of necrosis within the tumor. After determining microvessel counts of all patients, the average MVD was found as 89.3 (SD: \pm 28.74 ). This value was regarded as the cut-off value. Patients with microvessel counts below this cut-off value were classified as 'low MVD' (Figure 2), and patients with microvessel counts above this cut-off value were classified as 'high MVD' (Figure 3) (9, 10). Olympus BX51 (Tokyo, Japan) light microscope was used for counting microvessels. Microscopic photographs were captured by Olympus DP70 (Tokyo, Japan) camera.

\section{Statistical Method}

SSPS 20.0 for Windows (SPSS İnc. Chicago. IL. USA) software package was used to investigate whether there is a significant relationship between all the findings.

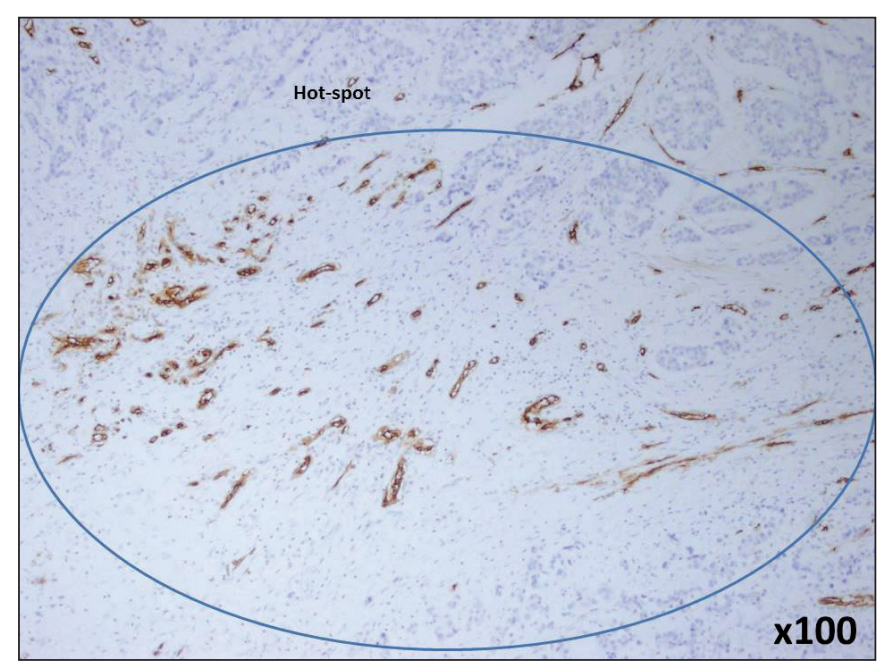

Figure 1: Immunohistochemical staining of an invasive ductal carcinoma, NOS with anti-CD34 antibody. The hot-spot with higher density of microvessels was identified and microvessels were counted in this area (CD34; x100). 


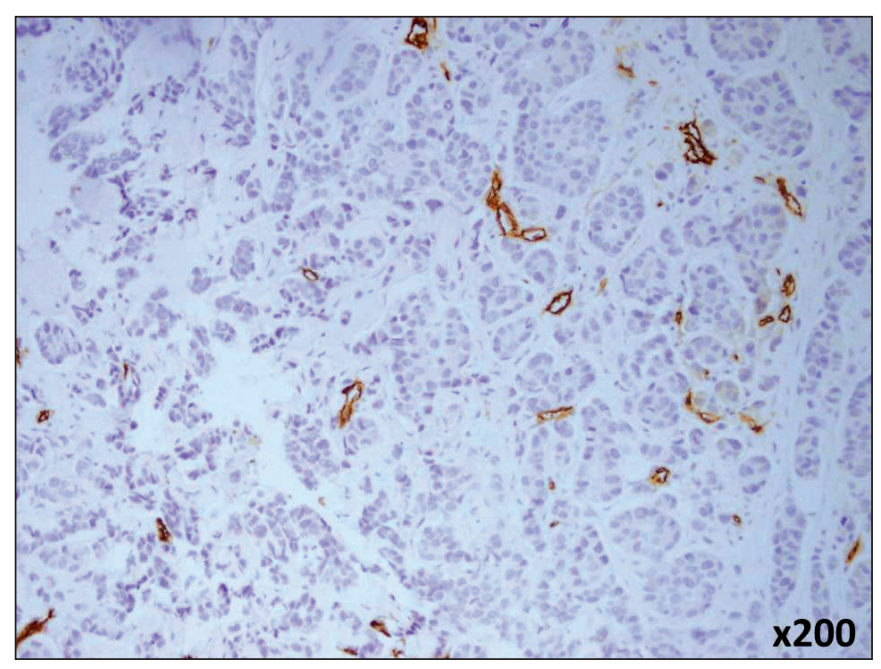

Figure 2: Low microvessel density in representative tissue sample of invasive ductal carcinoma, NOS (CD 34; x200).

Chi-square test was used to examine the relationship between MVD and other prognostic parameters. Those with a p-value smaller than 0.25 (tumor size, lymph node involvement, progesterone receptor status, lymphovascular invasion) in the univariate analysis were re-examined using the multivariate linear regression analysis model.

The error value was set as 0.05. $p$-values either higher or equal to 0.05 were considered to be statistically significant.

\section{RESULTS}

All of the patients included in the study were women with an average age of 51.8 (SD: \pm 11.9 years; age range, 26-80). Tumor size ranged from $0.7 \mathrm{~cm}$ to $10 \mathrm{~cm}$ and the average tumor size was $4.15(\mathrm{SD}: \pm 2: 03) \mathrm{cm}$. No lymph node metastasis was observed in $28 \%$ of the patients, while

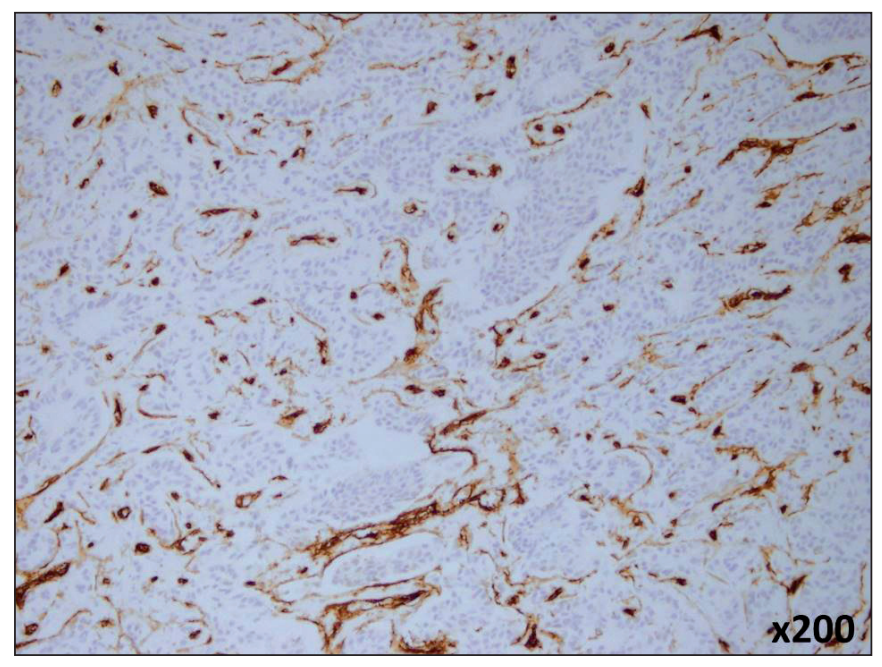

Figure 3: High microvessel density in representative tissue sample of invasive ductal carcinoma, NOS (CD 34; x200).

1-4 lymph node metastases were observed in $34 \%$ of the patients, 4-9 lymph node metastases were observed in $24 \%$ of the patients and $\geq 10$ lymph node metastases was observed in $14 \%$ of the patients, respectively. $2 \%$ of the patients were graded as grade $1,75 \%$ of them were graded as grade 2 , and the remaining $23 \%$ were graded as grade 3 , respectively. When MVD was calculated by anti-CD34 antibody, at least 31 and up to 185 microvessels were counted. High MVD was observed in $48 \%$ of the patients and low MVD was observed in the remaining $52 \%$, respectively. In our study, MVD was found to increase as tumor diameter increases $(\mathrm{p}<0.001)$. MVD was higher in patients with at least 10 lymph node metastases compared to those with no metastasis $(\mathrm{p}=0.05)$. The relationship between lymph node status and MVD is shown in Figure 4.

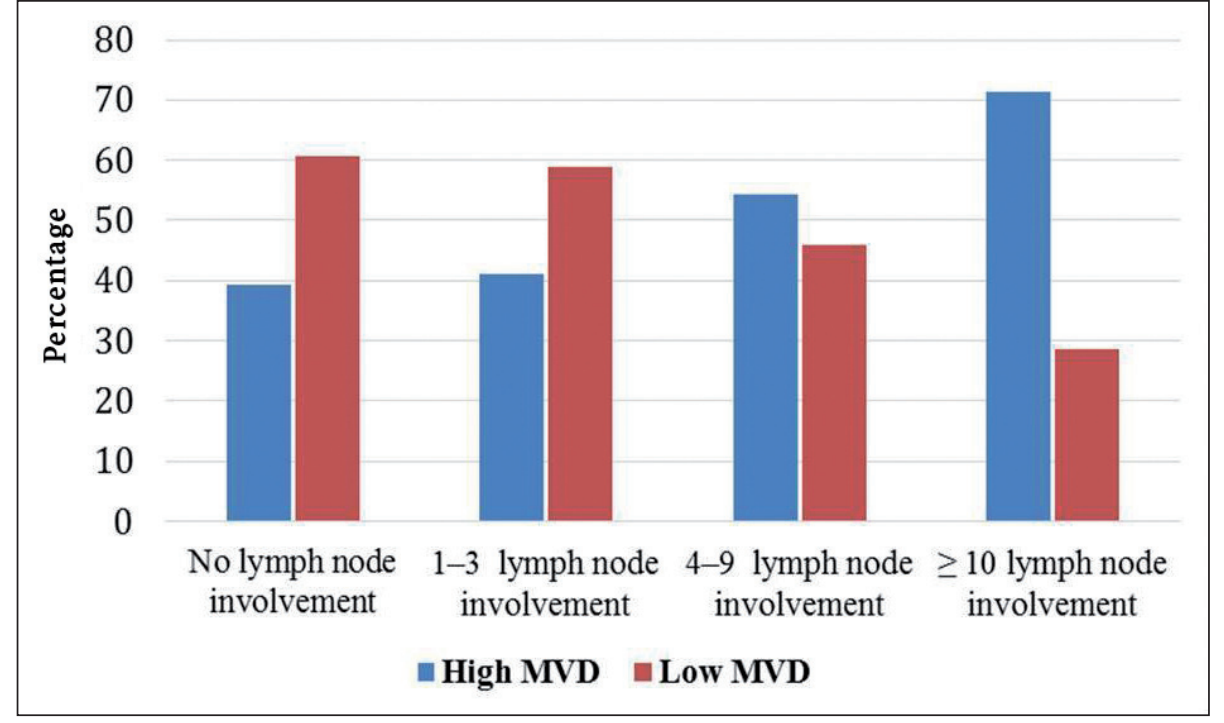

Figure 4: Comparison of MVD with lymph node involvement. 
No significant relationship was found between MVD and clinicopathologic parameters such as patient's age, histological grade, the presence of vascular invasion, estrogen-progesterone receptor status, human epidermal growth factor (HER2/neu) overexpression. The relationship between MVD and clinicopathological parameters is summarized in Table I.
The clinicopathological parameters with a p-value smaller than 0.25 in the univariate analysis were examined using the multivariate linear regression analysis model. Similar to the univariate analysis, the multivariate linear regression analysis showed a statistically significant relationship between MVD and tumor size and lymph node involvement. The results are summarised in Table II.

Table I: The relationship between clinicopathological parameters and MVD in patients with breast cancer

\begin{tabular}{|c|c|c|c|c|c|c|}
\hline \multirow{2}{*}{\multicolumn{2}{|c|}{ Variables }} & \multirow{3}{*}{\begin{tabular}{|l|}
$\mathbf{N}$ \\
45 \\
\end{tabular}} & \multirow{3}{*}{$\begin{array}{c}\mathrm{AMC} \pm \mathrm{SD} \\
86.33 \pm 25.74 \\
\end{array}$} & \multicolumn{2}{|c|}{ MVD } & \multirow{4}{*}{$\begin{array}{c}\text { p value } \\
0.573\end{array}$} \\
\hline & & & & \multirow{2}{*}{$\begin{array}{c}\text { High (\%) } \\
23(51.1) \\
\end{array}$} & \multirow{2}{*}{$\begin{array}{l}\text { Low (\%) } \\
22(48.9) \\
\end{array}$} & \\
\hline Age & $<50$ years of age & & & & & \\
\hline & $>50$ years of age & 55 & $88.49 \pm 31.12$ & $25(45.5)$ & $30(54.5)$ & \\
\hline \multirow[t]{3}{*}{ Tumor size } & $<2 \mathrm{~cm}$ & 15 & $71 \pm 16.56$ & $2(13.3)$ & $13(86.7)$ & \multirow{3}{*}{$<0.001$} \\
\hline & $2-5 \mathrm{~cm}$ & 60 & $85.25 \pm 27.84$ & $28(46.7)$ & $32(53.3)$ & \\
\hline & $5 \mathrm{~cm}$ & 25 & $102.88 \pm 30.06$ & $18(72)$ & $7(28)$ & \\
\hline \multirow[t]{2}{*}{ Lymph node involvement } & No lymph node involvement & 28 & $80.64 \pm 24.64$ & $11(39.3)$ & $17(60.7)$ & \multirow{2}{*}{0.05} \\
\hline & $\geq 10$ lymph node involvement & 14 & $106.36 \pm 33.08$ & $10(71.4)$ & $4(28.6)$ & \\
\hline \multirow[t]{2}{*}{ Estrogen } & \begin{tabular}{|l|} 
Positive \\
\end{tabular} & 46 & $87.41 \pm 32.21$ & $23(50)$ & $23(50)$ & \multirow{2}{*}{0.712} \\
\hline & Negative & 54 & $87.61 \pm 25.66$ & $25(46.2)$ & $29(53.8)$ & \\
\hline \multirow[t]{2}{*}{ Progesterone } & Positive & 58 & $83.29 \pm 26.53$ & $25(43.1)$ & $33(56.9)$ & \multirow{2}{*}{0.249} \\
\hline & Negative & 42 & $93.36 \pm 30.84$ & $23(54.8)$ & $19(45.2)$ & \\
\hline \multirow[t]{3}{*}{ HER2/neu } & Negative & 47 & $85.04 \pm 25.84$ & $20(42.6)$ & $27(57.4)$ & \multirow{3}{*}{0.476} \\
\hline & Equivocal & 15 & $92.80 \pm 35.43$ & $9(60)$ & $6(40)$ & \\
\hline & Positive & 38 & $88.50 \pm 29.66$ & $19(50)$ & $19(50)$ & \\
\hline \multirow[t]{2}{*}{ Lymphovascular invasion } & Yes & 82 & $88.34 \pm 28.73$ & $42(51.2)$ & $40(48.8)$ & \multirow{2}{*}{0.169} \\
\hline & No & 18 & $83.78 \pm 29.09$ & $6(66.7)$ & $12(33.3)$ & \\
\hline
\end{tabular}

AMC: Average number of microvessel count, SD: Standard deviation. MVD: Microvessel density

Table II: The relationship between clinicopathological parameters and MVD by multivariate linear regression analysis

\begin{tabular}{|l|c|c|c|c|c|}
\hline Model & B & SD & Beta & t & p \\
\hline Constant & 46.738 & 11.352 & & 4.117 & 0.000 \\
\hline Tumor size & 15.195 & 4.145 & 0.332 & 3.666 & $\mathbf{0 . 0 0 0}$ \\
\hline Lymph node involvement & 8.91 & 2.739 & 0.315 & 3.253 & $\mathbf{0 . 0 0 2}$ \\
\hline Progesterone & -7.477 & 5.227 & -0.129 & -1.43 & 0.156 \\
\hline Lymphovascular invasion & -8.333 & 7.057 & -0.114 & -1.181 & 0.241 \\
\hline
\end{tabular}

R: $0.484, R^{2}: 0.234$, F: 7.269 


\section{DISCUSSION}

The most important clinicopathologic factors influencing the biological behavior and treatment of the disease of breast cancer are patient's age, tumor size, tumor type, axillary lymph node involvement, the presence of vascular invasion, estrogen-progesterone receptor status and human epidermal growth factor (Her2/neu) overexpression (1113). Prognostic factors can be useful to identify poor clinical outcomes and select patients who will receive adjuvant therapy (14).

As known, angiogenesis plays a key role in tumor growth, invasion and metastasis. In recent years, the growing importance of targeted approaches in treating cancer highlights the target treatment options that inhibit angiogenesis in cancer treatment (15-17). Angiogenesis inhibitors slow and inhibit tumor growth and metastasis via different mechanisms. For example, anti-angiogenic drugs target directly pro-angiogenic molecules, while some of them inhibit angiogenic receptors, signal pathways or angiogenic external factors. Using anti-angiogenic drugs together or combining them with chemotherapeutic agents are more effective in treating breast cancer (18).

In this study, we have determined angiogenesis in invasive ductal carcinoma by counting microvessels using antiCD34 antibody and compared MVD that we have obtained from each patient with prognostic factors. We have found a statistically significant relationship between increasing tumor size and MVD $(\mathrm{p}=0.001)$. There are consistent studies (19-21) with our results in the literature as well as some studies $(16,22)$ found no significant relationship between MVD and tumor size and some studies found an inverse correlation between them (23).

When we compared MVD with lymph node involvement we have found that MVD was higher in patients with at least 10 lymph node metastasis compared to those with no metastasis $(\mathrm{p}=0.05)$. Similar to our results, there some studies found that high MVD is correlated with axillary lymph node metastases $(21,24,25)$. However, there are also some other studies found no relationship between MVD and axillary lymph node metastases $(16,26)$.

In our study, we have found no relationship between MVD and prognostic parameters such as patient's age, tumor size, histological grade, vascular invasion, estrogenprogesterone receptor status, human epidermal growth factor (HER2/neu) overexpression. In the literature, some studies have reported that there is no relationship between MVD and prognostic parameters such as patient's age (25, 27), histological grade (28), lymphovascular invasion (9), estrogen and progesterone receptor status (27), HER2/neu overexpression (27). On the other hand, there are also some other studies that found a significant relationship between high MVD and patient's age (29), high histologic grade (16, $25,27)$, presence of lymphovascular invasion (30), estrogen $(16,22)$ and progesterone receptor negativity (22) and HER2/neu overexpression (31).

As it can be seen, there are different results in the literature regarding the relationship between MVD and prognostic parameters. One of the reason of this may be using different antibodies such as CD34, CD31, Factor VIII and CD105 to highlight the microvessels $(24,32,33)$. In the literature, some studies reported that the anti-CD34 monoclonal antibody is more sensitive than the anti-CD31 antibody and anti-factor VIII-related antigens in the calculation of MVD in breast cancer $(31,32)$. Therefore, we used the anti-CD34 monoclonal antibody to calculate the MVD. Since we did not use any other antibodies in the calculation of MVD in breast cancer, we do not know whether our results were affected by this selection.

One another reason for having different results may be the calculation method of MVD. Weidner et al. have identified the hot-spot area with the largest number of microvessels at low magnification (x40 and x100) to determine MVD and counted microvessels in this area under a magnification of x200 (34). This method used by Weidner is used in many studies conducted on microvessel count $(16,28,35)$. Some authors have counted a single area under x200 or x 250 magnification, while some other counted a single area under x400 magnification (36-38). In this study, we have used the microvessel counting method used by Weidner.

In the tumoral area, heterogeneity of microvessel distribution may be another reason for the different results (39). Bosari et al. have shown that the number of microvessels counted in a single area is $20 \%$ more than the average number of microvessels counted in three areas (9). Heterogeneity of MVD is thought to be reduced with increasing number of areas counted (23). Examining each tumor tissue blocks and applying immunohistochemistry for all tumor tissue blocks may be useful in order to overcome the problem of heterogeneity. However, this is an expensive and time consuming process and it is difficult to maintain its sustainability in routine practice. In our study, after scanning the whole tumor sections, we have counted the microvessels in appropriate tumor tissue by immunostaining with anti-CD34 antibody. And also, all tissue samples that we have used to count microvessels were resected materials. Due to tumor heterogeneity, MVD should be determined in the resection materials and it should be avoided to determine MVD from biopsy specimens. 
Another reason for the different results between studies may be different cut-off values used to classify patients depending on their MVD. Some studies identify the cutoff value as the average number of microvessels $(9,27)$, but in other studies, the cut-off value is the median number of microvessels $(10,40)$. There are also some other studies accepted absolute values as the cut-off value $(36,41,42)$. In this study, we have accepted the average number of microvessels as the cut-off value. All these different cutoff values may be the main cause of different results by affecting the $\mathrm{p}$ value. However, we found similar results when we re-analyzed the data by accepting the median value as the cut-off value.

In conclusion, we have found MVD in invasive ductal carcinomas associated with tumor size and lymph node metastasis. However, there are different results regarding the relationship between MVD and prognostic parameters in the literature. These differences may be due to different microvessel counting methods and antibodies used to count microvessels. Since the exact identification of MVD may be helpful in estimating the impact of the antiangiogenic drugs used in the treatment of breast cancer and the selection of high-risk patients who will receive adjuvant therapy, the microvessel counting method and antibodies used to count the microvessels should be standardised.

\section{CONFLICT OF INTEREST}

The authors declare no conflict of interest.

\section{REFERENCES}

1. http://kanser.gov.tr/daire-faaliyetleri/kanser-istatistikleri/17932013-y1l1-türkiye-kanser-istatistikleri.html. T.C. Saglik Bakanligi Turkiye Halk Sagligi Kurumu Kanser Daire Baskanligi. Cancer statistics. Date of access: 08.04.2016

2. Fakhrejahani E, Toi M. Antiangiogenesis therapy for breast cancer: An update and perspectives from clinical trials. Jpn J Clin Oncol. 2014;44:197-207.

3. Weidner N, Carroll P, Flax J, Blumenfeld W, Folkman J. Tumor angiogenesis correlates with metastasis in invasive prostate carcinoma. Am J Pathol. 1993:143:401-9.

4. Srivastava A, Laidler P, Davies RP, Horgan K, Hughes LE. The prognostic significance of tumor vascularity in intermediatethickness (0.76-4.0 mm thick) skin melanoma. A quantitative histologic study. Am J Pathol. 1988;133:419-23.

5. Craft PS, Harris AL. Clinical prognostic significance of tumour angiogenesis. Ann Oncol. 1994;5:305-11.

6. Parham DM, Hagen N, Brown RA. Simplified method of grading primary carcinomas of the breast. J Clin Pathol. 1992;45:517-20.
7. Wolff AC, Hammond ME, Schwartz JN, Hagerty KL, Allred DC, Cote RJ, Dowsett M, Fitzgibbons PL, Hanna WM, Langer A, McShane LM, Paik S, Pegram MD, Perez EA, Press MF, Rhodes A, Sturgeon C, Taube SE, Tubbs R, Vance GH, van de Vijver M, Wheeler TM, Hayes DF; American Society of Clinical Oncology/College of American Pathologists. American Society of Clinical Oncology/College of American Pathologists guideline recommendations for human epidermal growth factor receptor 2 testing in breast cancer. Arch Pathol Lab Med. 2007;131:18-43.

8. Weidner N. Intratumor microvessel density as a prognostic factor in cancer. Am J Pathol. 1995;147:9-19.

9. Bosari S, Lee AK, DeLellis RA, Wiley BD, Heatley GJ, Silverman ML. Microvessel quantitation and prognosis in invasive breast carcinoma. Hum Pathol. 1992;23:755-761.

10. Fridman V, Humblet C, Bonjean K, Boniver J. Assessment of tumor angiogenesis in invasive breast carcinomas: Absence of correlation with prognosis and pathological factors. Virchows Arch. 2000;437:611-7.

11. Fitzgibbons PL, Page DL, Weaver D, Thor AD, Allred DC, Clark GM, Ruby SG, O’Malley F, Simpson JF, Connolly JL, Hayes DF, Edge SB, Lichter A, Schnitt SJ. Prognostic factors in breast cancer. College of American Pathologists Consensus Statement 1999. Arch Pathol Lab Med. 2000;124:966-78.

12. ESMO Guidelines Working Group, Kalaja VV. Recurrent or metastatic breast cancer: ESMO clinical recommendations for diagnosis, treatment and follow-up. Ann Oncol. 2007;18:9-11.

13. Lester SC, Bose S, Chen YY, Connolly JL, de Baca ME, Fitzgibbons PL, Hayes DF, Kleer C, O'Malley FP, Page DL, Smith BL, Tan LK, Weaver DL, Winer E; Members of the Cancer Committee CoAP. Protocol for the examination of specimens from patients with invasive carcinoma of the breast. Arch Pathol Lab Med. 2009;133:1515-38.

14. Wang J, Guo Y, Wang B, Bi J, Li K, Liang X, Chu H, Jiang H. Lymphatic microvessel density and vascular endothelial growth factor- $\mathrm{C}$ and $-\mathrm{D}$ as prognostic factors in breast cancer: A systematic review and meta-analysis of the literature. Mol Biol Rep. 2012;39:11153-65.

15. Nielsen DL, Andersson M, Andersen JL, Kamby C. Antiangiogenic therapy for breast cancer. Breast Cancer Res. 2010;12:209.

16. Bharti JN, Rani P, Kamal V, Agarwal PN. Angiogenesis in breast cancer and its correlation with estrogen, progesterone receptors and other prognostic factors. J Clin Diagn Res. 2015;9:5-7.

17. Li WW, Li VW, Hutnik M, Chiou AS. Tumor angiogenesis as a target for dietary cancer prevention. J Oncol. 2012;2012:879623.

18. Patel A, Hielscher A. Angiogenesis inhibitors in the treatment of breast cancer: Exploring avenues of new therapeutic targets. J Cancer Prev Curr Res. 2015;2:1-8.

19. Gasparini G, Weidner N, Bevilacqua P, Maluta S, Dalla Palma P, Caffo O, Barbareschi M, Boracchi P, Marubini E, Pozza F. Tumor microvessel density, p53 expression, tumor size, and peritumoral lymphatic vessel invasion are relevant prognostic markers in node-negative breast carcinoma. J Clin Oncol. 1994;12:454-66. 
20. Choi WW, Lewis MM, Lawson D, Yin-Goen Q, Birdsong GG, Cotsonis GA, Cohen C, Young AN. Angiogenic and lymphangiogenic microvessel density in breast carcinoma: Correlation with clinicopathologic parameters and VEGF-family gene expression. Mod Pathol. 2005;18:143-52.

21. Valkovic T, Dobrila F, Melato M, Sasso F, Rizzardi C, Jonjic N. Correlation between vascular endothelial growth factor, angiogenesis, and tumor-associated macrophages in invasive ductal breast carcinoma. Virchows Arch. 2002;440:583-8.

22. Biesaga B, Niemiec J, Ziobro M. Microvessel density and status of p53 protein as potential prognostic factors for adjuvant anthracycline chemotherapy in retrospective analysis of early breast cancer patients group. Pathol Oncol Res. 2012;18:949-60.

23. Tsutsui S, Kume M, Era S. Prognostic value of microvessel density in invasive ductal carcinoma of the breast. Breast Cancer. 2003;10:312-9.

24. Horak ER, Leek R, Klenk N, LeJeune S, Smith K, Stuart N, Greenall M, Stepniewska K, Harris AL. Angiogenesis, assessed by platelet/endothelial cell adhesion molecule antibodies, as indicator of node metastases and survival in breast cancer. Lancet. 1992;340:1120-4.

25. Wang G, Liang Y, Zhang H, Wang L, XU J. Microvessel density recognized by Endoglin as prognostic markers in breast carcinoma. Journal of Materials and Applications. 2014;3:41-6.

26. Kato T, Kimura T, Ishii N, Fujii A, Yamamoto K, Kameoka S, Nishikawa T, Kasajima T. The methodology of quantitation of microvessel density and prognostic value of neovascularization associated with long-term survival in Japanese patients with breast cancer. Breast Cancer Res Treat. 1999;53:19-31.

27. Erdem O, Dursun A, Coskun U, Gunel N. The prognostic value of p53 and c-erbB-2 expression, proliferative activity and angiogenesis in node-negative breast carcinoma. Tumori. 2005;91:46-52.

28. Ludovini V, Sidoni A, Pistola L, Bellezza G, De Angelis V, Gori S, Mosconi AM, Bisagni G, Cherubini R, Bian AR, Rodino C, Sabbatini R, Mazzocchi B, Bucciarelli E, Tonato M, Colozza M. Evaluation of the prognostic role of vascular endothelial growth factor and microvessel density in stages I and II breast cancer patients. Breast Cancer Res Treat. 2003; 81:159-68.

29. Marinho A, Soares R, Ferro J, Lacerda M, Schmitt FC. Angiogenesis in breast cancer is related to age but not to other prognostic parameters. Pathol Res Pract. 1997;193:267-73.

30. Kohlberger PD, Obermair A, Sliutz G, Heinzl H, Koelbl H, Breitenecker G, Gitsch G, Kainz C. Quantitative immunohistochemistry of factor VIII-related antigen in breast carcinoma: A comparison of computer-assisted image analysis with established counting methods. Am J Clin Pathol. 1996;105:705-10.
31. Vogl G, Bartel H, Dietze O, Hauser-Kronberger C. HER2 is unlikely to be involved in directly regulating angiogenesis in human breast cancer. Appl Immunohistochem Mol Morphol. 2006;14:138-45.

32. Martin L, Green B, Renshaw C, Lowe D, Rudland P, Leinster SJ, Winstanley J. Examining the technique of angiogenesis assessment in invasive breast cancer. Br J Cancer. 1997;76:104654.

33. da Silva BB, Lopes-Costa PV, dos Santos AR, de Sousa-Junior EC, Alencar AP, Pires CG, Rosal MA. Comparison of three vascular endothelial markers in the evaluation of microvessel density in breast cancer. Eur J Gynaecol Oncol. 2009;30:285-8.

34. Weidner N, Semple JP, Welch WR, Folkman J. Tumor angiogenesis and metastasis-correlation in invasive breast carcinoma. N Engl J Med 1991;324:1-8.

35. Kanjanapanjapol S, Wongwaisayawan S, Phuwapraisirisan S, Wilasrusmee C. Prognostic significance of microvessel density in breast cancer of Thai women. J Med Assoc Thai. 2007;90:282-90.

36. Obermair A, Kurz C, Czerwenka K, Thoma M, Kaider A, Wagner T, Gitsch G, Sevelda P. Microvessel density and vessel invasion in lymph-node-negative breast cancer: Effect on recurrence-free survival. Int J Cancer. 1995;62:126-31.

37. Axelsson K, Ljung BM, Moore DH 2nd, Thor AD, Chew KL, Edgerton SM, Smith HS, Mayall BH. Tumor angiogenesis as a prognostic assay for invasive ductal breast carcinoma. J Natl Cancer Inst. 1995;87:997-1008.

38. Medri L, Nanni O, Volpi A, Scarpi E, Dubini A, Riccobon A, Becciolini A, Bianchi S, Amadori D. Tumor microvessel density and prognosis in node-negative breast cancer. Int J Cancer. 2000;89:74-80.

39. Jitsuiki Y, Hasebe T, Tsuda H, Imoto S, Tsubono Y, Sasaki S, Mukai K. Optimizing microvessel counts according to tumor zone in invasive ductal carcinoma of the breast. Mod Pathol. 1999;12:492-8.

40. de Jong JS, van Diest PJ, Baak JP. Hot spot microvessel density and the mitotic activity index are strong additional prognostic indicators in invasive breast cancer. Histopathology. 2000;36:30612.

41. Hanahan D, Folkman J. Patterns and emerging mechanisms of the angiogenic switch during tumorigenesis. Cell. 1996;86:35364.

42. Heimann R, Ferguson D, Powers C, Recant WM, Weichselbaum RR, Hellman S. Angiogenesis as a predictor of long-term survival for patients with node-negative breast cancer. J Natl Cancer Inst. 1996;88:1764-9. 